\section{The Fluorine-19 NMR Spectrum of Methylthiotetrafluorophosphorane}

\section{Rolf B. Johannesen}

U.S. Department of Commerce, National Bureau of Standards, Washington, D.C. 20234, U.S.A

\section{S. C. Peake*}

Inorganic Chemistry Laboratory, South Parks Road, Oxford OX1 3QR, England

\section{R. SChMutzleR}

Lehrstuhl B für Anorganische Chemie der Technischen Universität Braunschweig

(Z. Naturforsch. 29 b, 699-700 [1974]; received May 15, 1974)

${ }^{19} \mathrm{~F}$ NMR, Magnetic nonequivalence, Computer-simulation, Accidental overlap

The low-temperature ${ }^{19} \mathrm{~F}$ NMR spectrum of the stereochemically non-rigid compound, $\mathrm{CH}_{3} \mathrm{SPF}_{4}$, shows three fluorine environments, one for the equatorial and two for the nonequivalent axial fluorine atoms. Each of the twelve lines of the upfield ${ }^{19} \mathrm{~F}$ (axial) resonance shows further fine structure, due to coupling between ${ }^{19} \mathrm{~F}$ and the protons of the $\mathrm{CH}_{3} \mathrm{~S}$ group. The center peaks of the two multiplet components reveal apparent quintet structure which, based on a computer simulation of the ${ }^{19} \mathrm{~F}$ spectrum of $\mathrm{CH}_{3} \mathrm{SPF}_{4}$, is rationalized in terms of accidental overlap of two quartets.

The ${ }^{19} \mathrm{~F}$ NMR spectrum of methylthiotetrafluorophosphorane, $\mathrm{CH}_{3} \mathrm{SPF}_{4}$, at low temperature shows signals from fluorine in three distinct environments ${ }^{1,2}$.

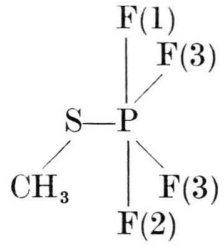

* Present address: Inorganic Development Section, The Radiochemical Centre, Amersham, Bucks., England.

Requests for reprints should be sent to Prof. Dr. R. Schmutzler, Lehrstuhl B für Anorganische Chemie der T, U., D-3.300 Braunschweig, Pockelsstr. 4.
The equatorial fluorines remain equivalent, while the two axial fluorines show chemical shifts and coupling constants which are distinct from one another. The signal from each of the axial fluorines is a doublet $\left(J_{\mathrm{PF}}\right)$ of triplets $\left(J_{\mathrm{F}(1) \mathrm{F}(3)} ; J_{\mathrm{F}(2) \mathrm{F}(3)}\right)$ of doublets $\left(J_{\mathrm{F}(1) \mathrm{F}(2)}\right)$. The upfield signal, $\mathrm{F}(2)$, is additionally split into multiplets by coupling to the methyl protons, while the analogous coupling to the downfield fluorine, $\mathrm{F}(1)$, shows itself as an unresolved broadening of all the lines. The multiplet splitting of the $\mathrm{F}(2)$ signal by protons is a quartet for the outer lines of the triplets, but apparently a quintet for the center lines of the triplets. This additional splitting of the center lines of the $\mathrm{F}(2)$ fluorines was initially puzzling, since a quartet was expected.

We report here the resolution of this apparent conflict by a computer simulation of the NMR spectrum of $\mathrm{CH}_{3} \mathrm{SPF}_{4}$. When this is done it becomes apparent that the wave functions of the $\mathrm{F}(3)$ fluorines, and hence of the entire molecule, occur in two non-interacting sets which are symmetric and anti-symmetric with respect to the plane of the molecule. Each of these wave functions leads to a quartet in the $F(2)$ region; it is accidental that the two quartets are so displaced as to give the appearance of a quintet. The computer simulation of the spectrum was done using the program UEAITR $^{3}$ with the values of chemical shifts and coupling constants given in the accompanying table. No iteration on measured line positions was done, since

Table. Constants used for computer simulation of $\mathrm{CH}_{3} \mathrm{SPF}_{4} \mathrm{NMR}$ spectrum.

\begin{tabular}{|c|c|c|c|}
\hline \multicolumn{2}{|c|}{ Chemical shiftsa } & \multicolumn{2}{|c|}{ Coupling constants ${ }^{\mathrm{b}}$} \\
\hline$\delta \mathrm{F}(1)$ & 14.1 & $J_{\mathrm{PF}(1)}$ & $-\quad 930.0 \mathrm{~Hz}$ \\
\hline$\delta \mathrm{F}(2)$ & 19.8 & $J_{\mathrm{PF}(2)}$ & -1088.0 \\
\hline$\delta \mathrm{F}(3)$ & 66.1 & $J_{\mathrm{PF}(3)}$ & -1075.0 \\
\hline$\delta \mathbf{P}$ & 34.2 & $J_{\mathrm{F}(1) \mathrm{F}(2)}$ & 19.1 \\
\hline \multirow[t]{6}{*}{$\delta_{\mathrm{H}}-$} & $2.26^{\mathrm{c}}$ & $J_{\mathrm{F}(1) \mathrm{F}(3)}$ & $91.0^{\mathrm{d}}$ \\
\hline & & $J_{\mathrm{F}(2) \mathrm{F}(3)}$ & $\pm 105.3^{\mathrm{d}}$ \\
\hline & & $J_{\mathrm{HF}(1)}$ & 1.3 \\
\hline & & $J_{\mathrm{HF}(2)}$ & 3.0 \\
\hline & & $J_{\mathrm{HF}(3)}$ & 0.0 \\
\hline & & $J_{\mathrm{HP}}$ & $24.8^{\mathrm{c}}$ \\
\hline
\end{tabular}

a Fluorine shifts in ppm upfield from internal $\mathrm{CFCl}_{3}$; phosphorus shift in ppm upfield from external $85 \%$ phosphoric acid; proton shift downfield in ppm from internal TMS.

b Lacking double resonance information, we assume ${ }^{5,6}$ all of the $J_{\mathrm{PF}}$ are $<0$. The relative intensities then agree only if all $\mathrm{J}_{\mathrm{FF}}$ are of the same sign.

c Reference 7. Measured at room temperature. A value of $12 \mathrm{~Hz}$ was used in the computer calculations since the correct value was not then available. The fluorine spectrum is unaffected by the value of $J_{\text {HP. }}$.

d Reference 4. 
the spectrum is very nearly first order. The computer calculated spectrum was in satisfactory agreement with the observed spectrum, including the additional lines in the centers of the $\mathrm{F}(2)$ triplets.

\section{Experimental}

Methylthiotetrafluorophosphorane was prepared under the conditions described by Peake and Schmutzler $^{2}$. No attempt was made to purify the thermally unstable compound. The ${ }^{19} \mathrm{~F}$ NMR spectrum was recorded at $-90{ }^{\circ} \mathrm{C}$, on a Perkin Elmer R 10 spectrometer at $56.4 \mathrm{MHz}$ without signal locking. Fluorotrichloromethane and toluene were used as an internal reference and solvent, respectively. The ${ }^{31} \mathrm{P}$ NMR spectrum was recorded at $-90^{\circ} \mathrm{C}$ on a Perkin Elmer R 10 spectrometer at $24.3 \mathrm{MHz}$ without signal locking. External $85 \%$ phosphoric acid was used as a chemical shift reference.

${ }^{1}$ S. C. Peake and R. Schmutzler, Chem. Commun. 1968, 1662 .

${ }^{2}$ S. C. Peake and R. Schmutzler, J. Chem. Soc. A 1970, 1049

${ }^{3}$ R. B. Johannesen, J. A. Ferretti, and R. K. Harris, J. Magn. Resonance 3, 84 [1970].

${ }_{4}^{4}$ Note the values of $J_{\mathrm{FF}}$ for the pair $\mathrm{F}(1) \mathrm{F}(3)$ and $\mathrm{F}(2) \mathrm{F}(3)$ were accidently interchanged in Ref. 1 and 2 .

5 D. L. van der Hart, H. S. Gutowsky, and T. C. Farrar, J. Chem. Phys. 50, 1958 [1969].

${ }^{6}$ S. L. Manatt, D. D. Elleman, A. H. Cowley, and A. B. Burg, J. Amer. Chem. Soc. 89, 4544 [1967].

7 D. H. Brown, K. D. Crosbie, J. I. Darragh, D. S. Ross, and D. W. A. Sharp, J. Chem. Soc. A 1971, 914

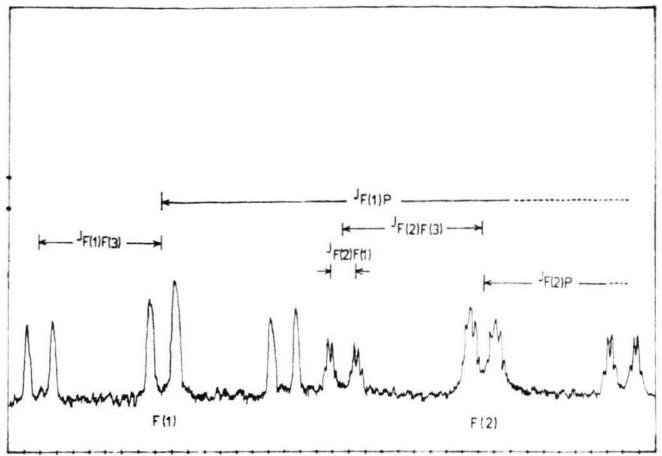

Fig. 1. ${ }^{19} \mathrm{~F}$ NMR spectrum of $\mathrm{CH}_{3} \mathrm{SPF}_{4}$ at $-90{ }^{\circ} \mathrm{C}$ (scale expansion of the lower axial fluorine atom region). $\mathrm{F}(1), \mathrm{F}(2)$ refer to the two axial fluorine atoms; $\mathrm{F}(3)$ refers to the two equatorial fluorine atoms.

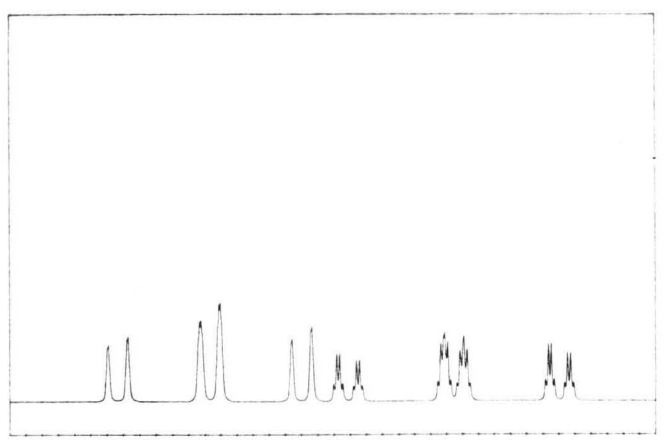

Fig. 2. Computer-simulated ${ }^{19} \mathrm{~F}$ NMR spectrum o $\mathrm{CH}_{3} \mathrm{SPF}_{4}$ (lower axial fluorine atom region). 